DELGADO, Jordi; CARNEVALI, Raúl, "El rol del juez penal en los acuerdos reparatorios: soluciones alternativas efectivas".

Polít. Crim. Vol. 15, No 29 (Julio 2020), Art. 1, pp. 1-24 [http://politcrim.com/wp-content/uploads/2020/07/Vol15N29A1.pdf]

\title{
El rol del juez penal en los acuerdos reparatorios: soluciones alternativas efectivas*
}

\section{The role of the criminal judge in the reparation agreement: effective alternative dispute resolution}

\author{
Jordi Delgado Castro \\ Profesor de Derecho Procesal, Universidad Austral de Chile \\ Doctor en Derecho, Universidad de Barcelona (España) \\ jordi.delgado@uach.cl \\ Raúl Carnevali Rodríguez \\ Profesor de Derecho Penal, Universidad de Talca \\ Doctor en Derecho, Universidad de Navarra (España) \\ rcarnevali@utalca.cl
}

\section{Resumen}

El artículo analiza la institución de los acuerdos reparatorios dentro del sistema procesal penal, reconociendo que se le entrega a la víctima y al imputado un papel más activo para la solución del conflicto y reclamando que le corresponde al juez desarrollar un rol de mayor preponderancia en la consecución de una solución pronta y satisfactoria para todos los intervinientes. Estos acuerdos se entienden como una manifestación del principio de intervención mínima del Derecho penal, al constituir un mecanismo menos lesivo para la resolver un problema penal. Se sostiene que resulta altamente conveniente la implicación del juez, asumiendo una función más activa y determinante para instar a las partes a alcanzar el acuerdo, dirigiendo para ello el debate. De este modo, al promover la conciliación, sobre todo en etapas tempranas, no solo sería eficaz para la descongestión del sistema, sino que además satisfaría de mejor forma a los involucrados en el conflicto, pues quien dirige y permite el acuerdo es un juez. En el trabajo se deja claro que esta actividad del juez no afecta la imparcialidad ni menos supone juzgar.

Palabras clave: acuerdos reparatorios, conciliación, juez penal.

\begin{abstract}
The paper analyzes Settlements with the victim within the criminal procedure system, understanding that victim and perpetrator get a more active role in conflict resolution. These settlements are understood as a manifestation of the Principle of minimum Intervention of Criminal law, as it constitutes a less harmful mechanism for solving a criminal problem.
\end{abstract}

\footnotetext{
* Este trabajo corresponde a parte de los resultados del Proyecto financiado por el Programa de Investigación Asociativa (PIA), Anillo SOC No 1406: "Mecanismos alternativos de resolución de conflictos como herramienta de modernización de la justicia. Construcción dogmática a partir de un análisis multidisciplinario".
} 
The authors wonder what should be the role of the Court on the materialization of the reparatory agreement. They reach the conclusion that Court involvement is highly advisable by taking a hands-on approach, urging the parties to reach an agreement and overseeing the debate. Thus, by promoting settlement, especially at early stages, not only the criminal justice system would be relieved, but also the parties at conflict would be better served, because who directs and allows the agreement is a Judge. The paper considers that by promoting settlement, a judge does not put impartiality at risk or much less, sentence.

Keywords: reparatory agreement, settlements, criminal judge

\section{Aproximación al tema. Propósito de los acuerdos reparatorios}

Los acuerdos reparatorios constituyen un fiel reflejo de una creciente tendencia hacia la privatización ${ }^{1}$ del conflicto penal. En efecto, el punto de partida clásico en las lecciones introductorias de Derecho procesal es caracterizar al objeto de debate en el proceso penal como algo público y, por tanto, indisponible. ${ }^{2}$ Pero lo cierto es que esta identificación tiene hoy un sentido más pedagógico que práctico. Justamente, sirve muy bien esta dicotomía para explicar conceptos como "lo público versus lo privado", "lo disponible versus lo indisponible" y, especialmente, el principio dispositivo. ${ }^{3}$

Pareciera, entonces, que en el proceso penal no existe ningún tipo de posibilidad de que víctima e imputado realicen actos de disposición sobre el objeto litigioso quedando, plenamente, a merced de lo que Ministerio Público y, finalmente, el juez decidan sobre hechos que por su cariz se convirtieron en parte de un acervo público social. ${ }^{4}$

Los acuerdos reparatorios son una forma de poner fin al conflicto penal. Lo más llamativo, ante este discurso, es que tienen un carácter bilateral y no asistido, de modo que son las partes quienes directamente y sin la necesidad de ningún facilitador ${ }^{5}$ de la comunicación

\footnotetext{
${ }^{1}$ En este sentido, hace tiempo que existen, especialmente en el Derecho comparado, postulados a favor de otorgar una mayor participación a los agentes principales del conflicto penal, para que estos sean quienes finalmente puedan satisfacer mejor las pretensiones propias. Así, por ejemplo MARSHALL (1999), p. 17: "Un proceso a través del cual las partes que se han visto involucradas o poseen un interés en un delito en particular, resuelven de forma colectiva la manera de lidiar con las consecuencias inmediatas de éste y sus repercusiones para el futuro".

${ }^{2} \mathrm{Si}$ bien es cierto que ya la doctrina más clásica ha convenido en señalar el difícil encaje del Derecho procesal entre lo público y lo privado, pero sin duda se dota de un alto contenido público, CASARINO (2011), pp. 12-13.

3 Adicionalmente, el paradigma chileno y su influjo español han velado desde siempre por conferir participación a los intereses concretos de las víctimas. Horvitz señala la importancia de las salidas alternativas como ejemplo de privatización del conflicto penal y explica el rol que ejerce la renuncia en el devenir del procedimiento penal, HORVITZ y LÓPEZ (2002) pp. 290-310 y 337-339.

${ }^{4}$ Lo explica, a propósito del enjuiciamiento de faltas, claramente DELGADO (2000), p. 110: "Un procedimiento se encontrará inspirado por el principio de oficialidad cuando tanto el inicio del proceso como su continuación dependan de la decisión de un órgano público, ya sea el Juez o el Ministerio Fiscal, y no de la voluntad de los particulares. Encuentra su pleno significado en su relación con el opuesto, principio dispositivo, según el cual los particulares litigantes tienen disponibilidad sobre el proceso, decidiendo tanto su comienzo como su finalización".

${ }^{5} \mathrm{Si}$ bien es cierto que no es la primera vez que se pone de manifiesto que, también, sería deseable un rol más activo del Ministerio Público en el fomento de arribo a soluciones alternativas satisfactorias para todos los
} 
resuelven la controversia con vocación de permanencia y ejecución del acuerdo en el tiempo $^{6}$. Una de las propuestas que desarrollaremos en este trabajo es que el juez, actualmente, ya cuenta con el espacio normativo suficiente como para desarrollar un rol más activo en la búsqueda de los acuerdos reparatorios. Por tanto, de lege lata, planteamos la necesidad que los jueces exploren con mayor entusiasmo esta salida alternativa al conflicto.

Para que este fenómeno pueda producirse, empero, el Estado debe renunciar, en parte, a su ius puniendi ${ }^{7}$ debido a que considera que, bajo determinadas condiciones, es mejor que las partes sean dueñas de su destino. ${ }^{8}$ En esencia, se parte de la premisa que la reparación pecuniaria, entre otras formas, ${ }^{9}$ cuando los hechos afectaron a bienes jurídicos disponibles de carácter patrimonial, lesiones menos graves o delitos culposos, puede resultar más oportuna que solucionar la controversia en forma pública. En este contexto, los intervinientes en el proceso penal recuperan su carácter de partes. ${ }^{10}$

Que así sea, puede entenderse porque el Derecho penal también interviene cuando no aplica penas o medidas de seguridad. En efecto, también debe resolver en qué casos renunciar a su

intervinientes en el proceso penal: "el fiscal debe promover la celebración de estos acuerdos como una forma de evitar que juicios de poca monta o de escasa relevancia jurídico-penal lleguen a juicio oral y, además, para evitar que el uso de este mecanismo de solución de conflictos quede entregado a la capacidad económica de los participantes, ya que en este escenario seria de uso exclusivo de las personas de mayor capacidad económica y escaparía a las finalidades que tuvo presente el legislador al momento de su incorporación". VIDELA (2010), p. 305.

${ }^{6}$ También destaca la doctrina, como MATURANA y MONTERO (2010), p. 19-20, que el acuerdo dentro del proceso penal requiere de la homologación del juez de garantía y responde a la necesidad de reparar el daño causado por el delito.

${ }^{7}$ Es más, como señala ROJAS (2001), p. 49: "los acuerdos reparatorios, esto es, la reparación acordada por las partes del conflicto penal, implican una alternativa (1) a la persecución penal y (2) a la pena. Por lo tanto, suponen una renuncia a la persecución penal y a la pena, vale decir a la búsqueda de la verdad procesal y a la imposición de la pena que se sigue de su establecimiento".

${ }^{8}$ En rigor, tal y como nos enseña SERRA (2008), p. 36 repasando la definición de jurisdicción como justa composición de Litis y, obligadamente, a Calamandrei, Carnelutti y Chiovenda, la jurisdicción no compone la Litis mediante el proceso, puesto que jurisdicción y proceso tienen por fin hacer prevalecer la pretensión de una parte sobre otra, "desarmando uno de los litigantes en cuanto le es impuesta la solución que el juez ha creído oportuno dar a favor de la otra parte". Y agregaba que "Sólo en raras ocasiones el juez tiende a "componer" la Litis; ello ocurre, por ejemplo, en los actos de conciliación en los cuales el juez debe procurar el acuerdo de las partes, prescindiendo del derecho aplicable; y precisamente tales actos de conciliación han sido considerados más propios de la jurisdicción voluntaria que de la contenciosa; lo que demuestra hasta cierto punto que la composición de litigios, si puede ser un resultado de la jurisdicción no es su nota característica, siendo además extraña a su esencia”.

${ }^{9}$ En esto, como acertadamente sostuvo FERNÁNDEZ (2001), p. 80, hay que atender a qué es lo que satisface a la víctima, pese a que a juicio de algunos pueda no parecer suficiente.

${ }^{10} \mathrm{Al}$ hacerlo, se materializan los postulados de lo que se ha llamado justicia restaurativa. Así por ejemplo, SAMPEDRO-ARRUBLA (2010), p. 90. "Esta cosmovisión surge en el ámbito de la victimología y la criminología y apunta a reconocer que la conducta punible causa daños concretos a las personas y las comunidades e insta a que la justicia repare efectivamente esos daños y a que tanto a la comunidad como a las partes en conflicto se les permita participar activamente en el proceso de su solución. Los programas de justicia restaurativa, por consiguiente, habilitan a las víctimas, al infractor y a los miembros afectados de la comunidad para que estén directamente involucrados en dar una respuesta al delito. El proceso restaurativo debe involucrar a todas las partes como aspecto fundamental para alcanzar el resultado restaurador de reparación y paz social". 
arsenal punitivo o reducir su aplicación. Como muy certeramente señaló Schünemann la función del Derecho penal no consiste sólo y únicamente en la protección de bienes jurídicos, sino además, en un complejo entramado que comprende el interés de la víctima y su protección, el interés del autor en su libertad y el interés de la comunidad en la prevención y seguridad jurídica. Agrega además, que si de dicho entramado se separa el interés en la protección y se lo absolutiza para la creación del Derecho, se pierde la teleología de la ley penal como 'Magna charta' del delincuente conforme lo entiende von Liszt. $^{11}$

Lo recién expuesto puede entenderse considerando lo que es naturaleza propia del sistema procesal acusatorio. En efecto, la introducción de mecanismos de solución de conflictos que no conllevan la imposición de una pena, como son, precisamente, los acuerdos reparatorios o la suspensión condicional del procedimiento, lo dejan muy claro. Lo esencial es la solución del conflicto, más que a la búsqueda de la verdad histórica, como sucede en el sistema inquisitivo, donde debe cumplirse rigurosamente el principio de legalidad, castigando si el hecho se subsume en algún tipo penal. En cambio, en el sistema acusatorio, lo que se procura es la verdad procesal y no tanto descubrir la verdad histórica. Ciertamente, no quiere decir que el sistema acusatorio no se dirija en ese sentido — se exige una verdad que permita verificar la imputación a fin de destruir la presunción de inocencia-, lo que se pretende significar es que no es su único objetivo. ${ }^{12}$ Es decir, el sistema acusatorio alcanza su pretensión, aun cuando no logre dilucidar la verdad absoluta, si se soluciona el conflicto y de esta forma se mantiene la paz social. Solución que, incluso, puede pasar por la no imposición de una pena, aunque el hecho históricamente sí sea un delito.

Puede decirse que la introducción de estos mecanismos de solución de conflictos materializan principios tan claros para el Derecho penal como es el de intervención mínima, pues se puede alcanzar una respuesta a través de un medio menos lesivo, pero igualmente eficaz; a través de una participación voluntaria y dialogante, es posible alcanzar los fines de pacificación social que se esperan del Derecho penal. ${ }^{13}$

En lo específico, el art. 241 Código procesal penal (en adelante CPP) es claro al establecer que le corresponde este poder negocial a imputado y víctima y que, por su parte el rol del juez parece limitarse a aprobarlo. ${ }^{14}$ Para arribar a esta decisión el juez llamará a una

${ }^{11}$ SCHÜNEMANN (1971), p. 365.

${ }^{12}$ BOVINO (2005), p. 60-63.

${ }^{13}$ Sobre el principio de intervención mínima, CARNEVALI, (2008), pp. 13 y ss.

${ }^{14}$ Es unánime la doctrina en destacar aquello, la letra de la ley parece clara y la jurisprudencia también parece evitar mayores consideraciones. Para ejemplo de aquello, Corte de Apelaciones de Concepción, Causa Rol 93-2014, de 4 de junio de 2014: "debe tenerse presente que es el imputado y la víctima quienes pueden convenir el acuerdo reparatorio, correspondiéndole al juez de garantía aprobarlo, a menos que en la audiencia a que se refiere el artículo 241 del Código del ramo, de oficio o bien a petición del Ministerio Público, pueda aquél negarse a dar su aprobación, pero cuando se está en presencia de las situaciones contempladas en el inciso tercero de dicho artículo, cuyo caso no es el de autos. Como el acuerdo se produce entre víctima e imputado, el incumplimiento de aquél por parte de este último facultará a la víctima para exigir su cumplimiento por la vía civil, como lo permite el artículo 243 del Código Procesal Penal, sin que esté permitido al Ministerio Público pedir la reanudación o continuar un procedimiento en el cual se ha arribado a 
audiencia en que se cerciorará que las partes son libres y conocen plenamente sus derechos. ${ }^{15}$ En realidad, la oportunidad procesal para intentar el acuerdo reparatorio podrá llevarse en la audiencia de formalización de la investigación, en una audiencia posterior convocada al efecto, o durante la audiencia de preparación del juicio oral (art. 245 CPP). Como fuere, observamos que se trata de una etapa pronta en que el juez no ha realizado actividades de verificación de los hechos $\mathrm{y}$, por lo tanto, solo tiene una aproximación somera a los mismos, de modo que está en condiciones de sentirse neutral respecto de la posición de las partes. Este estado le permite que su actividad conciliadora no sea cuestionada, en tanto, no se encuentra sesgada su visión de los hechos.

En esta labor, que en principio se presenta como "aséptica", el juez debe observar que se negocia sobre aspectos disponibles y dentro de los márgenes de lo que establece la ley. ${ }^{16} \mathrm{El}$ Ministerio Público, entre tanto, también deberá fiscalizar que, realmente, se trata de materias que permiten una suerte de disposición por las partes. ${ }^{17}$ Sin embargo, ambos actores del sistema deberán oponerse al acuerdo si no hay un consentimiento libremente prestado, o si, en realidad, existe un interés público relevante que amerita frustrar esta instancia y proseguir con el procedimiento. ${ }^{18}$ Como único criterio orientador, además de esa vaga referencia al interés público, la ley señala que la reiteración de los hechos por parte del imputado será un motivo de continuación con la persecución penal. ${ }^{19}$

un acuerdo reparatorio, de forma tal que sólo cabe cumplir con la obligación que el Código le asigna en el artículo 246 y no otra". Como podemos observar, la Corte destaca en este pasaje que el acuerdo es exclusivo de víctima y victimario sin corresponderle prácticamente protagonismo al juez, ni mucho menos al Ministerio Público.

${ }^{15}$ Así DUCE y RIEGO (2009), p. 345: “la intervención judicial opera como garantía, para las partes y para la sociedad en su conjunto, de que los acuerdos reparatorios no operarán como una forma de abuso de poder por parte de quienes se encuentren en una posición privilegiada respecto de su contraparte".

16 Se pretende, en suma, transparentar una vieja práctica de la que DUCE (2000), p. 159 se hacía eco indicando que se explicitaría la "práctica informal que se daba en el contexto de nuestro sistema inquisitivo, según la cual en un número significativo de casos (normalmente delitos patrimoniales no violentos) el acuerdo entre querellante y querellado se traducía en un escrito de desistimiento del querellante, el que finalmente llevaba al juez del crimen a decretar el sobreseimiento temporal o definitivo de la causa".

${ }^{17}$ Este tema ha generado, sin duda, un espacio a la polémica como recogen RODRÍGUEZ y PINO (2015), p. 387-388: "Como se indicó, estos acuerdos pueden recaer en hechos que afectaren bienes jurídicos disponibles de carácter patrimonial, consistieren en lesiones menos graves o constituyeren delitos culposos. Sobre lo que podría aludir la expresión poco feliz del legislador "bienes jurídicos disponibles de carácter patrimonial", la doctrina no es uniforme, reconociendo que "subsiste un espacio de interpretación", y que con esa expresión "la ley abrió el camino para una interpretación progresiva de este término de modo de favorecer una ampliación paulatina de casos susceptibles de acuerdos reparatorios". Como era de esperar, lo inasible del concepto aludido, en la práctica del sistema, no ha hecho sino develar nuevos flancos del principio de legalidad, pues facilita la celebración de acuerdos reparatorios por víctimas e imputados con relación a hechos penales que el MP debiera perseguir".

${ }_{18}$ Reivindicación que con fundamento sostenía CHAUÁN (2004), p. 136: "la cláusula de interés público prevalente, ofrece a la sociedad, representada por el Ministerio Público, el mecanismo para evitar los casos de abusos de esta institución".

19 Probablemente, en esa ausencia de criterios claros, el Fiscal Nacional dictó el instructivo $\mathrm{N}^{\mathrm{o}} 34$ que contempla las materias en que los fiscales favorecerán los acuerdos reparatorios; aquellas en que los fiscales evaluarán con detención su procedencia y aquellos supuestos en que se opondrán. Sin embargo, muchas de las reglamentaciones de este carácter se vieron afectadas por el Oficio 133/2010, de 31 de marzo que dejó sin efecto estos criterios. Sin embargo, resulta útil revisar dicho instructivo a los efectos de comprobar el catálogo 
De llegar a perfeccionarse el acuerdo, entendiendo que es aprobado por el juez, tan pronto como se cumplan las condiciones establecidas en el mismo o, en su defecto, se garantice ese cumplimiento, se dictará el sobreseimiento definitivo extinguiéndose, total o parcialmente, la responsabilidad penal del imputado, según corresponda. A su vez, ejecutoriada esta resolución se podrá solicitar el cumplimiento ante el juez de garantía, siguiendo lo establecido para los procedimientos incidentales de cumplimiento del Código de Procedimiento Civil. ${ }^{20}$

La regulación positiva de este instituto, termina estableciendo efectos relativos entre las partes que suscriban los acuerdos (art. 244 CPP) y consagrando un sistema de registro en el que se debe dejar constancia de la aprobación del acuerdo reparatorio. De este modo, se podrá conocer si el imputado cumple, o no, el acuerdo. ${ }^{21}$

\section{Juez imparcial y proceso penal}

Del conflicto de intereses de relevancia jurídica que necesita ser resuelto se desprende la dualidad de partes y contraposición de sujetos que requieren al Estado para que solucione su contienda. Es uno de los elementos que fluye naturalmente de la definición de jurisdicción entendida como un poder-deber del Estado y, adicionalmente, se corresponde con las teorías de la sustitución que sirven para definir a la jurisdicción y que, en esencia, se corresponden con el brocardo latino nemo iudex in sua causa. ${ }^{22}$ En este sentido, uno de los principales elementos, independientemente de la teoría que se adopte, innegablemente es la ajenidad del juez respecto del conflicto objeto de debate.

Para poner fin a ese conflicto, el Estado dispone de un juez natural, juez legal o preconstituido por la ley para que, como órgano imparcial e independiente, resuelva, en este caso, una vulneración al ordenamiento jurídico. Esta garantía es parte de lo que debemos entender por debido proceso, y significa una de las manifestaciones concretas del art. $19 \mathrm{~N}^{\mathrm{o}}$

de delitos, bien jurídico protegido y la recomendación que desde el Ministerio Público se hizo en algún momento.

${ }^{20}$ Cuestión no exenta de problemas de aplicación práctica por los que, incluso, actualmente se ingresó un Proyecto de Ley (Boletín 11.481-07) en que uno de sus objetivos es corregir errores forenses en que: "A su vez, las víctimas de delitos susceptibles de acuerdos reparatorios, pueden verse impedidas de continuar la prosecución penal en contra del imputado, en caso de que éste incumpla las condiciones contraídas, quedando incluso solamente con la posibilidad de efectuar cumplimiento incidental ante el juez de garantía, pero sin la posibilidad de continuar con la acción penal".

${ }^{21}$ Como señalamos, pese a que ha generado algunas dudas de interpretación lo cierto es que las Cortes del país entienden que el incumplimiento del acuerdo reparatorio, permite reanudar la persecución penal. A modo de ejemplo, Corte de Apelaciones de Chillán, RIC 1220-2016, de 14 de julio de 2016: “A su vez, el objetivo del acuerdo reparatorio es el sometimiento efectivo y responsable a la obligación contraída por el imputado con la víctima en cuanto a satisfacer aquello a que se obligó y no a formular un simple compromiso nominativo a cuya ejecución quedará luego obligado el ofendido. Tal es la razón por la cual, sin perjuicio del derecho que tiene la víctima y querellante, en su caso, de optar por ejecutar libremente el acuerdo ante el juez civil, le asiste también la facultad de pedir su revocación y de seguir adelante con el proceso penal, en cuyo decurso tiene también asegurada la indemnización de los daños civiles".

22 Esta idea es explicada magistralmente por SERRA (2008), pp. 37-40, valiéndose de los principales exponentes de esta teoría Chiovenda, Alfredo y Hugo Rocco, Betti y Zanzucchi. 


\section{Polít. Crim. Vol. 15, № 29 (Julio 2020), Art. 1, pp. 1-24. [http://politcrim.com/wp-content/uploads/2020/01/Vol15N29A1.pdf]}

3 de la Constitución Política de la República. De esta manera, se asegura la imparcialidad y el desinterés del juez en el pleito. En efecto, la razón de ser sustancial de esta norma reside en que la indicación del juez competente no se produzca post factum, lo que comportaría un aumento en el riesgo de haber elegido una opción concreta cuyo objetivo fuere apuntar en una dirección determinada. ${ }^{23}$

Ahora bien si partimos de la base de un juez natural, imparcial y predeterminado por ley, es importante delimitar bien qué funciones desarrolla y con qué objetivo, puesto que, la principal hipótesis que sostenemos en este trabajo es que le debe corresponder al juez un rol más activo en aquellas instancias en las que la situación jurídica ${ }^{24}$ permite que las partes desarrollen un rol protagónico frente al conflicto jurídico.

Es claro que, en ningún caso, proponemos una vuelta al modelo anterior en que el mismo juez investigaba, acusaba y juzgada, puesto que lo cierto es que esa conformación jurisdiccional no resiste análisis. ${ }^{25}$ Pero superado el purismo propio de un estado incipiente de desarrollo de nuestro sistema procesal, ${ }^{26}$ es que, hoy en día, existe (considerando a todos los ámbitos reformados en su conjunto) una creciente potenciación de la labor conciliadora de los jueces y su rol directivo ${ }^{27}$ del proceso que, en algún modo, legitiman esta suerte de privatización de los intereses en debate. ${ }^{28}$

${ }^{23}$ En este mismo sentido VALLESPÍN (2002), p. 71, explica que: "El Juez que intervenga y decida un proceso, para responder al modelo constitucional de proceso justo, ha de venir predeterminado según normas legales predeterminadas. Las normas sobre competencia objetiva, funcional y territorial, así como las que regulan el reparto o distribución interna de los asuntos entre los Juzgados y Tribunales, son las que sirven para delimitar esta exigencia en cada caso concreto". Para complementar aquella necesidad con una prevención "Las Leyes Orgánicas y Procesales deben ser sumamente escrupulosas para impedir que actúe o juzgue un iudex suspectus, estableciendo las adecuadas causas de exclusión, abstención o recusación. Ello es así, porque este derecho al juez imparcial que va implícito en el derecho al juez ordinario predeterminado por la ley, encuentra su genuina protección constitucional en el marco del derecho a un proceso con todas las garantías".

${ }^{24}$ Siguiendo a SERRA (2008), p. 259 respecto a la naturaleza del proceso, del procedimiento y sus consecuencias: "al ser vida social es indispensable que estas reglas sean lo más elásticas posibles, pueden modificarse de acuerdo a la materia que por ellas circula, pues como se ha afirmado correctamente sólo es óptimo el ordenamiento procesal en el que el proceso puede cambiar su estructura orgánica para conformarse con las exigencias concretas de cada caso".

${ }^{25}$ Lo sintetizaba muy bien NEIRA (1993), p. 14: "La relación procesal básica se da entre el juez y el reo, la primera característica del proceso inquisitivo consiste, precisamente, en que las funciones de defender, acusar y sentenciar son cumplidas por una persona, el juez". Ello conducía a situaciones insostenibles, ya que: "La actividad del juez que es la nota distintiva de este tipo de procedimientos lo lleva no sólo a investigar la comisión del delito y la responsabilidad del inculpado, sino que le impone el deber de establecer los hechos ocurridos, aun cuando esto lo lleve a comprobar la inexistencia del delito o la inocencia del acusado".

${ }^{26}$ Resulta importante destacar que cualquier reforma a la "estrella" de las reformas procesales chilenas, podía despertar mucho interés y quizá temores, probablemente, infundados. Así, DUCE (2013), p. 139, a propósito de la reforma impulsada en 2012, expresaba: "En lo positivo, no es una propuesta de "contrarreforma" o que intente "desmantelar" los principios básicos del sistema, lo que aleja los temores iniciales a propósito de los anuncios y declaraciones de las autoridades. Los cambios propuestos, sin perjuicio de mi discrepancia con varios de ellos o la necesidad de perfeccionar otros, en su gran mayoría son razonables y efectivamente podrían producir mejoras en el funcionamiento del sistema o reforzar garantías necesarias".

${ }^{27}$ Así, MASCIOTRA (2014), p. XXI: "El juez debe dejar de ser un "convidado de piedra", en palabras de Mauro Cappelletti, para transformarse en verdadero y real "director del proceso", asumiendo un rol protagónico, al conferírsele iniciativas probatorias, a fin de lograr la máxima eficacia en su función y que de él emane una decisión justa(...) Este rol protagónico del juez es -reiteramos- una consecuencia inevitable de 
El problema, entonces sobre el rol del juez, está sin duda en que no parece que se ajuste al debido proceso un procedimiento en que este tercero imparcial adopta una función que cruza la línea entre juzgar y "derrotar" a una de las partes. ${ }^{29}$ Así, el juez debe realizar su función principal desde la equidistancia de las posiciones, ${ }^{30}$ sin embargo, no significa aquello que no pueda participar y dirigir el debate ${ }^{31} \mathrm{y}$, en este particular, involucrarse estimulando con propuestas los acuerdos ${ }^{32}$ en tratar de alcanzar una solución temprana del conflicto, al menos, bajo determinadas circunstancias, ${ }^{33}$ que por lo demás se encuentran reguladas en la ley.

Lo execrable, entonces, es que un juez sea parcial. ${ }^{34}$ En este sentido, adolecería de incompetencia subjetiva y las causales están claramente definidas en nuestro ordenamiento jurídico. ${ }^{35}$ Pero más allá de aquello, las prohibiciones en el proceso penal llegan a rayar lo

la publicización del proceso, concepción que asume la mayor parte de la doctrina procesal moderna y en la que se inscriben los nuevos códigos y reformas procesales".

${ }^{28}$ Explica muy bien este fenómeno HORVITZ y LÓPEZ (2002), pp. 290-291.

${ }^{29}$ La problemática sobre las potestades oficiosas del juez está muy bien expuesta en HUNTER (2007), pp. 207-210. Pero es importante reseñar que el debate se ha centrado siempre en la aportación de prueba, por parte del juez y sus límites. Es ahí, probablemente, donde el juez puede llegar a perder su imparcialidad, puesto que su actividad puede favorecer a una de las partes, por sobre la otra.

${ }^{30}$ Característica repetida por la doctrina, por ejemplo, BORDALÍ (2009), p. 284.

${ }^{31}$ A propósito del tratamiento de la imparcialidad en el caso español, RAMOS (2014), pp. 87 y 88, explica cómo el Tribunal Constitucional español, finalmente, ha ido dotando de contenido a esta máxima y en rigor: "ha tenido que señalar que las actuaciones que implican adoptar medidas limitativas de derechos o la apertura del juicio oral comprometen la imparcialidad del Tribunal. No así, en cambio, las meras actuaciones formales o de impulso del procedimiento, que vienen exigidas por las normas legales".

${ }^{32}$ Consideramos que la madurez de nuestro sistema y de la función jurisdiccional ha derrotado una visión más cauta en que hace pocos años se predicaba con acierto (desde el punto de vista temporal): "siendo procedente el acuerdo no parece posible admitir que el juez lo rechace por considerar que los términos del mismo son insuficientes o, por el contrario, excesivos. Si la víctima está dispuesta a aceptar como reparación bastante unas simples disculpas públicas o si el imputado está dispuesto a pagar una importante suma de dinero que supera con creces los daños ocasionados, es una cuestión de su incumbencia y no de la del juez" (BLANCo et al. (2005), p. 69). Cabe destacar que Matus ha sostenido que el Ministerio Público puede asumir un rol más activo para alcanzar acuerdos, estableciendo para ello un sistema de mediación MATUS (2011), p. 76 y ss. Sobre la mediación en este ámbito, LIBEDINSKY (2001), p. 153.

${ }^{33}$ Superada la fase en que las partes son las absolutas dueñas del proceso, se le reconoce en el siglo XXI al juez la dirección formal del proceso, ver MONTERO (2014), pp. 28-29. En general, donde existe discusión es si es que puede el juez decretar prueba de oficio, conviniéndose, en general, que en el ámbito penal esta potestad le está excluida. Sin embargo, resulta imprescindible revisar a PICÓ (2007), pp. 129-159, quien demuestra que bajo determinadas circunstancias incluso la prueba de oficio no hace perder la imparcialidad, ni atenta contra el principio acusatorio. En definitiva, entonces, lo que debe separarse es la acusación del enjuiciamiento propiamente tal, para no vulnerar el brocardo ne procedat iudex ex officio. En contra de la posibilidad de decretar prueba de oficio en tanto en Chile se habría optado por un proceso adversarial o acusatorio puro, puede consultarse, BORDALÍ (2009), p. 289.

${ }^{34}$ Se ha especificado que esta condición alcanza a tres conceptos interrelacionados: impartialidad (el juez no ha de ser parte), imparcialidad (el juez no ha de tener interés en el resultado del pleito) e independencia (respecto de otros poderes del Estado, y en relación a los superiores jerárquicos). En este sentido, puede consultarse ALVARADO (1989), p. 261.

${ }^{35}$ Si bien es cierto, como apunta ECHEVERRÍA (2010), p. 295, que el diseño legislativo está pensando en que los jueces, en general, no caigan en causales de inhabilidad. Probablemente, no porque el sistema los considere como seres superdotados (VALDÉS, (2004), s/p), sino porque la prudencia nos conduce a pensar que ningún juez ostenta causas que le generen parcialidad como regla general. 
absurdo: quizá no sea el momento de desarrollar esta idea, pero lo cierto es que llama poderosamente la atención que quien ha de juzgar y decidir, no pueda sino solamente realizar preguntas aclaratorias ${ }^{36} \mathrm{y}$, en la práctica, se haya convertido en una instancia realmente frágil, puesto que un supuesto cruce de esa tenue línea significaría prejuzgamiento y determinaría la nulidad de todo el juicio. ${ }^{37}$

El principal escollo ante esta argumentación que apuesta por una participación más activa de los jueces, es la regulación de los art. $195.8^{\circ}, 196.10^{\circ}$ y 320 del Código Orgánico de Tribunales (en adelante, COT). Efectivamente, las reglas contenidas en el COT apuntan a que el juez solamente emita su juicio en el momento de la dictación de la sentencia, una vez analizadas las alegaciones y su relación con las pruebas. ${ }^{38}$ Pero hilando fino, lo que se prohíbe es prejuzgar anticipadamente, emitir una opinión sobre el pronunciamiento y sentido en que se va a adoptar el fallo. ${ }^{39}$

Nada obsta, sin embargo, a que el juez pueda -hablando en genérico, como potestad conciliadora- promover acuerdos y emitir sus dichos fundados, por ejemplo, en los escritos de discusión. ${ }^{40}$ Más complejo es entender si esto lo puede hacer después de haber "visto" la prueba, pero todavía no es momento de ir más allá. ${ }^{41}$

${ }^{36}$ Hay supuestos en que la línea se traspasa. Son los casos en que los jueces preguntan elaborando su teoría del caso, de una parte, y con un tono excesivamente directo que, parece esconder una idea preconcebida, más que recabar información. Así, puede consultarse PALOMO (2010), pp. 314-320.

37 Al respecto resulta bien interesante resaltar, como lo ha hecho MONTERO (2014), p. 97, que existen prácticas que sin duda no son de recibo: “en la jurisprudencia española es algo claro que el tribunal penal, si quiere mantenerse imparcial, no puede, después del interrogatorio de las partes interrogar ni a los imputados ni a los testigos "durante diez minutos formulándole sesenta preguntas de naturaleza claramente acusatoria".

38 Sin embargo, lo cierto es que el proceso de generación de la convicción es algo más complejo. Así, por ejemplo, COUTURE (2010), pp. 228-236, expone que existe una primera fase llamada juicio prima facie en que se depura si en el supuesto de hecho hay visos de encontrarnos con una contravención al ordenamiento jurídico; una segunda en que se realiza un examen crítico de los hechos; una tercera en que se realiza la subsunción de los hechos en el Derecho y, finalmente, una última en que se adopta la decisión. Lo cierto es que nuestro proceso penal trata de soslayar la primera de las fases descritas, pero es importante reconocer que el juez adopta su toma de posición durante el desarrollo, casi completo, del procedimiento.

39 En un interesante fallo la Suprema Corte de Justicia de la Provincia de Buenos Aires señaló: "se ha precisado que el prejuzgamiento se configura en aquellos supuestos en que el juez en el mismo proceso ha anticipado o dejado traslucir su opinión sobre el fondo de la causa u otro aspecto que sólo corresponde decidir en la sentencia definitiva. Es decir que para que se configure esta causal debe existir: a) un pronunciamiento en la causa referido a un prejuzgamiento expreso; b) recaído sobre la cuestión de fondo a decidir; c) en el mismo proceso y d) en oportunidad en que no corresponde emitir opinión" (Suprema Corte de Justicia de la Provincia de Buenos Aires, Inconst. Ord. 6873/2010, de 15 de junio de 2011).

${ }^{40}$ En este orden de ideas, es bueno recordar que el propio CHIOVENDA (2005), p. 31 al describir la jurisdicción voluntaria y la función conciliatoria expresaba: "A esta actividad de jurisdicción voluntaria debemos añadir la que el Estado ejercita para prevenir los litigios conciliando a las partes. Considerando la importancia de esta función, el Estado se la ha reservado para sí, porque tanto mayor será la probabilidad de que la conciliación se logre cuanto mayor sea la autoridad de la persona que la intenta" (...) y, añadía, "La conciliación es el efecto de un acuerdo de voluntades, si bien provocado; es, por lo tanto, acto de disposición".

${ }^{41} \mathrm{Si}$ bien es cierto, que las medidas para mejor resolver tienen su principal sentido para cuando el juez ha observado la prueba y entiende que le faltan elementos para generar su convicción, de una parte, y se encuentra obligado a fallar para no vulnerar la regla del non liquet. Entonces, en rigor resulta un argumento absurdo, puesto que como señala PICÓ (2007), pp. 112-113: "postular la protección de la imparcialidad, como fundamento de la inactividad probatoria del juez civil, y otorgar a la vez dicha facultad a los jueces y 
Ante este panorama, ¿puede el juez hacer propuestas para la solución del conflicto y estimular un acuerdo reparatorio?

\section{La misión del juez en el proceso penal}

Lo cierto es que no parece tan sencillo saber cuáles son los alcances específicos -más allá de la obvia función de juzgar -que ha de desarrollar el juez en el proceso penal. ${ }^{42}$ Para empezar observamos que pudiera ser que más de un juez tenga participación en el mismo procedimiento, con roles diversos en función de la oportunidad en la que nos encontremos. ${ }^{43}$ Pero en una aproximación inicial podemos afirmar que la función del juez en el ámbito penal se traduce en aplicar el poder punitivo en un modo racional y equilibrado. ${ }^{44}$

En este reparto de papeles y funciones trataremos de delimitar qué labores corresponden al juez de garantía, en tanto que es este a quien le atañe, en su caso, aprobar los acuerdos reparatorios. En especial, queremos dilucidar qué alcances ostenta respecto a la función constitucional y su aterrizaje legal, para poder establecer si los jueces de garantía pueden participar de los acuerdos reparatorios con un papel protagónico.

El punto de partida, entonces, está en el art. 76 de la Constitución Política de la República que entrega, indubitadamente dos grandes categorías: resolver causas criminales, en este caso, y hacer ejecutar lo juzgado. Por razones que escapan a este trabajo no nos referiremos a la segunda función esencial. ${ }^{45} \mathrm{El}$ primer mandato constitucional que se le entrega a un juez es la resolución de causas.

Resolver causas criminales, desde su definición, ${ }^{46}$ significa solucionar un problema y, específicamente aplicado al derecho, decidir sobre un conflicto o parte de este: así decidir la aplicación del derecho al caso concreto. En nuestro contexto, entonces, se concreta en dar solución a un conflicto de relevancia jurídica tomando la decisión ajustada a derecho. ${ }^{47}$ Este enfoque se corresponde casi sin reparos con la definición de sentencia definitiva que

tribunales de otros órdenes jurisdiccionales, especialmente del penal, y contencioso-administrativo, significa reconocer y legitimar que estos jueces y tribunales puedan ser parciales si proceden de oficio a practicar prueba, conclusión ésta por nadie compartida".

${ }^{42}$ Existen algunas aproximaciones, como RUA y GONZÁLEZ (2018), pp. 80 y ss.

${ }^{43}$ Resulta especialmente acertado el análisis que realiza ROMERO (2017), pp. 109-116.

${ }^{44}$ CERDA (2007), p. 129.

${ }^{45}$ Puede consultarse, empero, MORALES et al. (2015), passim.

46 La segunda acepción del diccionario de la Real Academia de la Lengua Española indica: "Decidir algo o formar la idea o el propósito firme de hacerlo. Resolvimos pernoctar allí. El tribunal resolvió su ingreso en prisión. U. t. c. intr. El juez resolvió a su favor". Disponible en: http://dle.rae.es/srv/fetch?id=WBV06OC [visitado: 11/03/2019].

${ }^{47}$ En palabras de COLOMBO (2014), p. 345: "Desde el momento en que las partes, de común acuerdo, no pudieron evitar o resolver un conflicto de intereses de relevancia jurídica y solicitaron la intervención del tribunal, lo hicieron con el preciso fin de que éste fuera quien lo resolviera. La sentencia definitiva es el acto previsto por la Constitución y la ley para resolver la cuestión o asunto que ha sido objeto del juicio. Mediante ella el juez aplica la norma decisoria litis al caso concreto sometido a su decisión, singularizando la norma abstracta para solucionar el conflicto, esto es, declara el derecho, su acto es iuris dictio". 
propone el Código de Procedimiento Civil. Pareciera, entonces, que la esencia de la jurisdicción se materializa en aquella forma de operar. ${ }^{48}$

Ahora bien, sabemos que la dictación de una sentencia definitiva no es, en exclusiva, la forma de solucionar un conflicto ${ }^{49}$, y que tampoco es la única resolución que existe en el ordenamiento jurídico. ${ }^{50}$ Por lo tanto, un juez bien pudiera resolver una contienda jurídica, mediante otro tipo de cauce. Así, el juez debe solucionar el asunto, pero pudiera conducir su actuación por distintos caminos. ${ }^{51}$ En esencia, reivindicamos en este punto, una participación que aproveche la experiencia "judicial" de los jueces que permita llegar a acuerdos, surtir de elementos de realidad, arribar a diálogos fructíferos sin traspasar, en ningún caso, el estímulo intencionado para convertirse en un juez que da órdenes para poner fin al conflicto.

El COT parece encorsetar la función a las tareas específicas de conocer, juzgar y hacer ejecutar lo juzgado ${ }^{52}$ (art. 1 COT). Para esta finalidad, en el ámbito de suyo propio del juez de garantía, ${ }^{53}$ se entregan diferentes herramientas. El art. 14 COT establece la resolución de asuntos al indicar que el juez puede dictar sentencia en el procedimiento abreviado; en los

${ }^{48}$ De hecho, entre las muchas definiciones de jurisdicción analizadas desde la óptica del Derecho romano encontramos, casi siempre, esta nota común "declaración de la norma aplicable". Ver DE MARTINO (1937), p. 149.

49 Por ello CERDA (2007), p. 133 habla, con propiedad, de que el juez de garantía ostenta toda la potencialidad de la jurisdicción y no se refiere solamente a la facultad de dictar sentencia.

${ }^{50}$ De hecho, acudiendo al último informe sobre Justicia desarrollado por el INE (2016), indica que en el ámbito penal las causas terminan en primer lugar por sobreseimiento y la sentencia definitiva significa un $18,6 \%$ de los motivos de término.

${ }^{51}$ En este sentido, "En todo caso, el punto que nos interesa destacar en esta parte es que, aunque tanto el proceso penal de los países europeos continentales citados, como también el norteamericano, no corresponden en teoría a modelos procesales puros, en ambos casos, pero con distintos énfasis, existen espacios relevantes para las salidas alternativas. Ello, porque la concepción del proceso penal que manejan está orientada, en alguna medida, por la idea de que éste es un ámbito para la solución de conflictos sociales y no solamente un mecanismo destinado a la averiguación de la verdad histórica y la sanción de los delincuentes", DUCE y RIEGO (2009), pp. 292-293.

52 Debemos, siquiera un momento, detenernos a reflexionar sobre los fines del proceso y, en definitiva, las necesidades del justiciable cuando acude al auxilio de los tribunales de justicia. En este sentido, es necesario reivindicar una mayor atención a las alternativas jurisdiccionales distintas a la sentencia definitiva y, por cierto, a la función ejecutiva, tantas veces descuidada. Daremos un ejemplo que gráfica, especialmente, esto último: "Me refiero especialmente a la obra del Prof. Ramos Méndez sobre "Enjuiciamiento Civil" que lleva como subtítulo explicativo "Como gestionar los litigios civiles". A más de uno ha tenido que sorprender el planteamiento metodológico de comenzar por la ejecución. A poco de su publicación un estimado colega iberoamericano durante un congreso me comentó: “(pero) ¿cómo es que el Prof. Ramos comienza su nuevo manual por la ejecución?". Le parecía que eso es como poner el carro delante de los bueyes cuando se debe proceder, como enseñaba Bártolo a obtener primer la sentencia favorable de la que nace la "actio iudicati" y sólo después la ejecución". Mi respuesta fue que de esa obra había que entender su metodología y que no era una obra académica al uso, un Manual expositivo de la asignatura, sino que enseñar cómo se gestionan los litigios civiles. Si ejercieras la abogacía -le argumenté al estimado colega- te sería más fácil entenderlo" VÁZQUEZ (2014), p. 42.

${ }^{53}$ Por otra parte, como destacan MATURANA y MONTERO (2010), p. 167: "Asegurar los derechos del imputado y demás intervinientes en el proceso penal, de acuerdo a la ley procesal penal (artículo 14, letra a) COT). Esta competencia constituye la principal misión del juez de control de garantía respecto del imputado, la víctima y los testigos, conforme a lo previsto en el artículo 83 de la CPR, 14 letra a) del COT y en los artículos $6^{\circ}, 9^{\circ}$ y 70 del CPP". 
casos en que se ejerza actividad jurisdiccional motivado por una falta penal de las reguladas en el Código Penal o en la Ley de Alcoholes; en los asuntos de responsabilidad penal juvenil, adicionalmente; en los supuestos que acontezcan a propósito del Sistema de Justicia Militar y, finalmente, para analizarlo en conjunto con el CPP, para conocer y fallar respecto a los procedimientos establecidos en el Título I del Libro IV del CPP.

Por su parte, el CPP concede espacios de resolución de causas en los asuntos que se tramiten mediante procedimiento simplificado (conocimiento y fallo -art. $388 \mathrm{CPP}$ ); procedimiento monitorio (si es fundado y se acoge); procedimiento por delito de acción privada; y procedimiento abreviado. Adicionalmente, hay que entender que se comprenden dentro de las formas de solucionar el conflicto y pasan necesariamente por la actividad del juez de garantía, entre otros, los acuerdos reparatorios y la suspensión condicional del procedimiento.

Sin embargo, en ningún caso existe una norma que ahonde en los detalles de cómo debe realizarse esta actividad. El elemento que aflora naturalmente es el proceso, en rigor, el procedimiento. Pero ni en uno ni en otro caso, hay una norma jurídica que sea tan precisa para otorgar todas las directrices que ha de seguir "matemáticamente" el juez. El grado de indeterminación más o menos amplio de las normas jurídicas provoca, en muchas ocasiones que algunas prácticas sean diferentes, según el tribunal ante el que se tramita. Existen normas que regulan el contenido de la sentencia, pero no parece tan claro saber cómo se deben comportar los operadores jurídicos ante los diferentes métodos alternativos de resolución del conflicto. Aquí encontramos uno de los mayores contrasentidos de nuestro ordenamiento jurídico: se regula minuciosamente el juicio ordinario y la gran mayoría de causas se resuelven por un cauce distinto. Inevitablemente, volvemos al principio: ¿puede un juez participar e incluso estimular un acuerdo reparatorio en forma directa? La respuesta, en gran medida, debe estar inspirada en que habiendo normas que resguardan valores intransables como la imparcialidad del juzgador, su actuación se encuentra suficientemente controlada legalmente y aquello que exceda de una actuación prudente podrá ser susceptible de ser revisado por un superior jerárquico. ${ }^{54}$

Adicionalmente, la doctrina ${ }^{55}$ ha podido describir qué funciones cumple el juez de garantía y podemos inferir que el juez no es un mero espectador reconociéndose funciones como: "dirigir el debate, ordenar la rendición de la prueba en los asuntos que le corresponda juzgar, exigir el cumplimiento de las formalidades previstas para los actos procesales, moderar la discusión de los intervinientes, pero sin coartar el derecho de defensa de éstos y ejercer las facultades disciplinarias destinadas a mantener el orden y decoro durante el debate".

\footnotetext{
54 En este caso, concordando con la aproximación de VON WRIGHT (1997), p. 33: “la cuestión de las lagunas no es una cuestión de lógica. Es más bien una cuestión de aceptación o no aceptación de determinadas metanormas".

${ }^{55}$ MATURANA Y MONTERO (2010), p. 169.
} 


\section{Un juez que logre acuerdos}

Existiendo la ocasión de satisfacer el interés de la víctima, ${ }^{56}$ por una parte, y minimizando la expresión del Derecho penal, en los términos expuestos supra, lo más probable es que un rol activo del juez, en especial del juez de garantía, ${ }^{57}$ fuera absolutamente deseable. ${ }^{58}$ No debemos perder de vista que la entidad del asunto del que propiamente enjuicia el juez de garantía, es de menor gravedad en comparación con los tipos delictivos de los que conoce el Tribunal de Juicio Oral. ${ }^{59}$ Por lo tanto, una salida alternativa es sin duda aconsejable. ${ }^{60}$

Adicionalmente, devolver, en cierto modo, el conflicto a las partes debe generar un efecto positivo para la imagen de la Justicia que, inevitablemente, refuerza su mejor cara al obtener soluciones que complacen a las $\operatorname{partes}^{61} \mathrm{y}$, finalmente, se convierte en un instrumento de racionalización de los recursos y de flexibilidad de las soluciones. ${ }^{62}$

Pero entrando a los argumentos sobre el fondo, básicamente hay que señalar que el juez no pierde su imparcialidad y es eso, precisamente, lo que quiere proteger el ordenamiento jurídico. ${ }^{63}$ En concreto, los ejemplos más palmarios se encuentran en el ordinal octavo del art. 195 COT puesto que inhabilita a un juez para fallar de un asunto en los casos en que emite dictamen habiendo visto los antecedentes. Además, el art. $196.10^{\circ}$ que indica como causal de recusación el haber emitido dictamen sobre la cuestión, con conocimiento de ella.

\footnotetext{
${ }^{56}$ Sobre la revalorización del interés de la víctima, véase DUCE (2014), pp. 740-744.

${ }^{57}$ Que supere lo descrito por CASTRO (2017), p. 377: "En cuanto a las facultades judiciales para aprobar o rechazar el acuerdo parece conveniente, teniendo presente el interés privado preponderante, que el tribunal se limite a constatar que concurren los requisitos legales sin examinar el mérito del AR (acuerdo reparatorio)".

${ }^{58}$ Lo expone con diáfana maestría MONTERO (2014), p. 35: "Esta confusión ha llevado incluso a pretender negar al juzgador penal lo que quiere reconocerse al juez civil. Parte de nuestra doctrina auspicia la ampliación de las facultades materiales de la dirección del juez civil, de modo que éste pueda contribuir con las partes a la comprobación de los hechos pudiendo practicar prueba de oficio, pero esa misma parte de la doctrina pretende que el juez penal no pueda decidir de oficio la práctica de medios de prueba".

59 De hecho las corrientes que abogan por la justicia restaurativa descartan de plano que sus fundamentos residan en la menor gravedad de los hechos, o de las penas aparejadas a los mismos. Por lo tanto, si es que, en cierto modo, somos capaces de renunciar a la persecución penal en casos graves, no debiera suponer un gran esfuerzo aceptar la premisa en supuestos de menor entidad. Puede consultarse, MÁRQUEZ (2009), p. 59-75, p. 60 .

60 Uno de los argumentos más repetidos en relación a los fundamentos más importantes para el establecimiento y aplicación de las medidas alternativas es "la necesidad de racionalizar la persecución penal pública frente a los escasos recursos disponibles y las características de última ratio y subsidiariedad del mismo". A su vez se destacan, con igual acierto, razones de convivencia social y la tutela directa de los intereses de la víctima (DUCE y RIEGO (2009) p. 295).

${ }^{61}$ En palabras de FERREIRO (2005), p. 415: "Supone en cierta medida una devolución del conflicto, del modo propugnado por la Victimología que pretende reincorporar el interés de la víctima al Derecho Penal, pero sin que el Estado pierda el control sobre la aplicación de éste".

${ }^{62}$ En esa misma línea, algo por el estilo avizoraba DUCE (2000), p. 171: "La suspensión condicional del procedimiento y los acuerdos reparatorios en el nuevo Código Procesal Penal", "es de esperar que los distintos actores del sistema de justicia criminal tiendan a interpretar las normas que regulan tales instituciones de una manera flexible que permita su utilización de manera amplia".

63 Así, el artículo $1^{\circ}$ del Código Procesal Penal consagra expresamente al tribunal imparcial. Pero de no haberlo hecho VALDECABRES (2004), p. 115 explica que, aun cuando no se encuentre consagrado legalmente, la imparcialidad es un atributo inherente a la función jurisdiccional.
} 
Tanto uno como otro supuesto, apuntan a que el juez podría perder su imparcialidad, por haber formado ya su criterio, con anterioridad al conocimiento acabado de la causa. ${ }^{64}$ No significa que su razonamiento sea errado, sino que ha sido obtenido sin la tramitación completa de un procedimiento y, por lo tanto, existe el riesgo que ese enjuiciamiento sea errado. Por otra parte, no parece de recibo que la Justicia se pueda permitir el lujo de tener entre sus mejores elementos a personas que divisan o perciben soluciones al conflicto sin un acabado procedimiento y, como mínimo, sin respetar los límites esenciales del derecho a la prueba.

Pero en este contexto, parece realmente importante destacar que en una etapa temprana, el juez puede realizar propuestas de solución del conflicto ${ }^{65}$ sin, necesariamente, afectar su imparcialidad. ${ }^{66}$ De hecho, solamente habiendo asistido a una fase de discusión (oral o escrita) en la que se puede imbuir de los principales aspectos que determinan las peticiones de las partes, podríamos plantear aquella hipótesis. Por lo tanto, el hecho que la parte imputada esté dispuesta a negociar, no tiene que ser considerada por el juez como asunción de responsabilidades $y$, consecuentemente, no debiera nublar su juicio.

Entonces, el primer requisito para que esto pueda suceder es que, en efecto, se trate de un momento inicial del procedimiento para evitar que la información oscurezca, contamine, o más bien, adelante, el juicio del órgano jurisdiccional. ${ }^{67}$ Con esta afirmación queremos posicionarnos $\mathrm{y}$, en el fondo, sostener que el acto de enjuiciamiento se va adquiriendo con el desarrollo mismo del procedimiento. De este modo, parece más aconsejable que en los estadios preliminares a la prueba sean las oportunidades en que el juez, quien no se ha provisto de mayor profundidad en el asunto, pueda tratar de obtener acuerdos de una forma más neutral.

Así las cosas, lo cierto es que la propuesta que pueda promover el juez escuchando a las partes va a estar dotada de imparcialidad, atendido su desconocimiento profundo de la causa y, entonces, solamente estará guiado por su experiencia como profesional del derecho. ${ }^{68}$ Esta intervención del juez, además, ha de permitir evitar que se realice una

\footnotetext{
${ }^{64}$ Cuestión que, en la etapa procesal en la que nos encontramos (inicial) está fuera de toda duda.

${ }^{65}$ Proponemos, entonces, superar aquella visión que describe a nuestros jueces como agentes que controlan la legalidad (y no el mérito) de los acuerdos reparatorios, para destacar la función componedora de la litis que se asemeje más a un rol análogo al que juega el juez en la conciliación. Puede contrastarse con la conclusión quinta que sostiene Zárate, de la que, en definitiva, abogamos por avanzar otro escalón. Véase, ZÁRATE, (2000), pp. 125-146.

${ }^{66}$ Así como lo destaca VALDECABRES (2004), p. 152, lo que se trata de resguardar con la imparcialidad es que el juez se haya formado una determinada convicción acerca de la participación del imputado en un hecho punible.

${ }^{67}$ Ciertamente, probar que un juez adolece de falta de imparcialidad es una cuestión de difícil prueba, pero en un momento inicial más todavía. Así, ORTELLS (1993), pp. 175-213, p. 202: “(la) falta de imparcialidad des difícil que tenga éxito, porque requiere la prueba de un factor interno o espiritual como es el de un determinado prejuicio del juez respecto del caso".

68 Para vulnerar esa conformación inherente al proceso: "La imparcialidad del Juez consiste en no estar, en general, ni haber estado, en el caso concreto, en posición de parte. Y se está en posición de parte cuando anímicamente se toma o ha tomado partido de modo visible exteriorizado a favor o en contra de alguno de los litigantes, o cuando, exista o no una parcialidad anímica, se desarrolla o se ha desarrollado una actividad o se
} 


\section{Polít. Crim. Vol. 15, No 29 (Julio 2020), Art. 1, pp. 1-24. [http://politcrim.com/wp-content/uploads/2020/01/Vol15N29A1.pdf]}

negociación extrajudicial que solamente tenga por objeto beneficiar al más poderoso, o al que tiene posibilidades económicas de lograr vencer la responsabilidad penal con dinero. ${ }^{69}$ Esto significa una propuesta novedosa que, en algún momento, se situó como una posibilidad de actuación en manos del Ministerio Fiscal. ${ }^{70}$

Además, debemos reparar en un detalle, no menor, que nuestro legislador ha conformado en el ámbito de la conciliación. Así, tanto el art. 263 del Código de Procedimiento Civil, como el 453 del Código del Trabajo establecen una previsión para que las opiniones que manifieste el juez, no se tengan como inhabilitantes para seguir conociendo de la causa. Sin embargo, ni en la Ley $\mathrm{N}^{\mathrm{o}}$ 19.968, ni en el CPP se establecen dichas salvedades. Empero, el artículo 273 del CPP hace una remisión a las normas que regulan la materia en el orden civil, por lo que, entonces, deberíamos entenderlas incorporadas. Es más, incluso si aquella remisión no se hiciera, también se podría comprender incluida por lo establecido en el artículo $3^{\circ}$ del Código de Procedimiento Civil.

De este modo, debemos reparar en dos consideraciones: la primera es que en etapas tempranas se habla de opiniones y no de dictámenes y, en segundo lugar, la previsión sobre las opiniones y su eventual efecto sobre el desarrollo de la causa, ni tan siquiera ha sido replicada expresamente en todas nuestras disposiciones procesales, por lo que podríamos inferir que no existe consenso acerca de que emitir tales opiniones pueda afectar la imparcialidad del juez. ${ }^{71}$

A mayor abundamiento, lo cierto es que la forma de soslayar ese eventual conflicto entre lo que el juez declara y su condición de prejuzgamiento es especialmente débil. Dicho de otro modo, no porque una norma jurídica diga que un juez no pierde su imparcialidad al emitir un pronunciamiento, aquello va a suceder. Así las cosas, lo cierto es que el juez no pierde su imparcialidad, porque así una norma lo establezca, sino más bien debido a que nunca estuvo comprometida, como criterio de realidad. No se cumple con la finalidad para la que fueran creadas las causales de implicancia y recusación, puesto que proponer acuerdos salvo en los casos en que se realicen venciendo derechamente a una de las partes- no puede generar duda o sospecha respecto de la potencial parcialidad del juez. ${ }^{72}$

desempeña o se ha desempeñado una función estructuralmente alineada a uno u otro lado de la contienda" LÓPEZ (2013), p. 52.

${ }^{69}$ Se combatiría este fenómeno que bien describe CHAUÁN (2007), pp. 235-237.

70 Así, DEL RÍO y ROJAS (1999), p. 428, exponían entre las críticas a los acuerdos reparatorios la desigualdad en la distribución de los recursos económicos y el eventual efecto que ello podría producir para que los poderosos optaran a esta salida alternativa. Para evitar un uso fraudulento del mecanismo proponían: "la fijación de un planteamiento o criterio político criminal, por parte del ministerio público, que asuma estas diferencias socioconómicas adoptando medidas concretas para estimular la mediación entre el imputado y la víctima, y promover acuerdos reparatorios posibles de cumplir por el imputado, de acuerdo a sus circunstancias particulares".

71 Traspasar los límites del rol mediador en pro de lograr acuerdos es lo que ha censurado la doctrina: "Los poderes no pueden entenderse como un permiso para adquirir el proceso en desmedro de las partes, por lo que las opiniones que emita el juez en el marco de la función conciliatoria no lo inhabilitarán en la medida que no impliquen una anticipación de su fallo o no demuestren ideas preconcebidas a favor de una u otra parte". PALOMO y MATAMALA (2012), pp. 459-456.

${ }^{72}$ GALÁN (2005), p. 27. 
En una etapa temprana, el juez en su fuero interno puede haberse ido formando una aproximación jurídica de lo que aconteció respecto de un conflicto, pero solamente por su formación profesional, lo cierto es que no ha podido alcanzar la solución del asunto, sin antes presenciar la producción de la prueba. No puede haber prejuzgado quien no tiene los elementos suficientes para formarse un juicio $y$, en un momento tan inmaduro del procedimiento, a lo sumo podrán hacerse conjeturas que, sin duda, el juez no necesita refrendar en una resolución de término de conflicto.

Finalmente, hay que considerar que el artículo 273 CPP conduce a que el juez realice el llamado obligatorio a conciliación contemplado para las acciones de orden civil. En otro orden de cosas, pero muy en relación con los acuerdos reparatorios, se observa cómo los jueces tienen asignada una tarea que implica el uso de sus destrezas negociales, ya que deben proponer bases de arreglo. Nadie piensa que sea una vulneración de la imparcialidad, atendida la oportunidad. De este modo, no hacemos sino reforzar nuestro postulado: los jueces deben lograr acuerdos. ${ }^{73}$

\section{4. ¿Cuándo el juez deja de ser imparcial?}

Probablemente nunca. Lo más seguro es que el juzgador no pierda su imparcialidad en tanto no parece habitual que el juez esté relacionado directamente con el fondo del asunto. Ahora bien, en el caso que un juez vaya a tomar el rol de amigable componedor, lo más prudente, parece, es que desarrolle este cometido en una etapa temprana del procedimiento, de modo que su propuesta pueda ser lo más neutral posible.

Una vez que se ha comenzado a depurar el objeto de debate y empieza la actividad probatoria es insostenible para el Estado de Derecho pedir actos de fe a favor de los juzgadores. Como señalamos, lo más probable es que el juez siga sin perder la imparcialidad, pero ante hechos que van alumbrando un camino, ninguna parte va a poder entender que una actividad "componedora" está despojada de una teoría de caso. El efecto que puede generar una propuesta habiendo observado actividad probatoria coarta la libertad de arribo a una decisión satisfactoria. ${ }^{74}$

\footnotetext{
${ }^{73}$ Sigue, de esta forma, más vigente que nunca una cita decimonónica: "El juez avenidor debe ser una persona prudente, imparcial, de buena fe y sano consejo, que inspire ascendente y señale a las partes, prontas a lanzarse en la arena judicial, todos los peligros, todos los sinsabores y pérdidas a que se exponen; que les indique los funestos efectos a que puede conducirles su empeño en seguir un litigio, les aconseje e ilustre sobre la avenencia que les es más conveniente; que trate de excitar la piedad de un acreedor sobrado riguroso, y de despertar la buena fe en el ánimo de un deudor desconfiado, hiriendo los resortes más a propósito para conmoverlo, e infundiéndole ideas de equidad y de justicia que le hagan aproximarse a los límites de una transacción o conciliación equitativa", DE VICENTE Y CARAVANTES (1856), passim.

${ }^{74}$ En estos casos, es en los que puede suceder aquello que magistralmente narró Calamandrei: “a veces el juez se esfuerza para encontrar a posteriori los argumentos lógicos más idóneos para sostener una conclusión previamente sugerida por el sentimiento", CALAMANDREI (2009), p. 157.
} 
Por ejemplo, cuando un juez ya ha escuchado a un testigo y hace preguntas aclaratorias, en el fondo ya está buscando obtener los hechos que le conduzcan a la decisión, por lo que ya no está en condiciones de motivar acuerdos sin valoraciones sobre el fondo. ${ }^{75}$

Entonces, sea el tipo de procedimiento que sea, la imparcialidad solamente se ve absolutamente inmaculada hasta completar la etapa de discusión (alegaciones iniciales de las partes). Si se tratase de un procedimiento escrito tras los escritos de réplica y dúplica, en el caso de un proceso preminentemente oral el momento oportuno ha de ser inmediatamente después de la narración de la acusación y defensa que realiza el juez. Podría verse, incluso antes de los óbices procesales o excepciones de previo y especial pronunciamiento, aunque si realmente tienen un carácter procedimental, nada obstaría a que se realice después.

A partir de ese momento, en que comienzan a desplegarse actos de estrategia litigiosa, el juez debe adoptar un rol mucho más contemplativo, en especial en el orden penal. Lo cierto es que pese a que se produce el fenómeno de la llamada paradoja procesal del siglo XXI, ${ }^{76}$ la prudencia debe ser la tónica imperante cuando se debate sobre la libertad de las personas. $^{77}$

Lo contrario nos puede llevar a un juez que se abandera por una hipótesis fáctica o jurídica propia. Así, por ejemplo el juez que bajo el manto protector del iura novit curia introduce una nueva calificación jurídica y la refrenda en su sentencia solamente inserta en el procedimiento una incongruencia y una sospecha de falta de la imparcialidad debida. ${ }^{78}$

En rigor, en todo caso, probablemente no pudiera alcanzar una categoría más "grave" que la sospecha, puesto que un juez que busca prueba, por ejemplo, no se vuelve parcial por este hecho solamente. $^{79}$

\footnotetext{
${ }^{75}$ De hecho, sería un juez que no está en óptimas condiciones para fallar sobre el fondo del asunto, atendida su eventual pérdida de la imparcialidad, en el modo señalado por BORDALÍ (2009), pp. 289 quien expone que nuestro sistema procesal penal, sobre la base del adversarial o acusatorio puro no consagra poderes probatorios oficiosos. Al contrario, destaca los casos de Alemania, España, Francia, Holanda, Italia y Portugal. Entre los clásicos, encontramos que WACH (2016), pp. 61-65, ya exponía respecto de la Ordenanza Procesal Civil Alemana de 1875 que no encontraba problemas respecto de formular preguntas a las partes, del mismo modo que pedirles que complementaran sus escritos iniciales, o señalarles la insuficiencia probatoria cuando fuera necesario. Nuestra propuesta, como hemos podido describir es mucho más modesta: permitir al juez fomentar el diálogo en una etapa procedimiental temprana.

${ }^{76}$ Excelente tesis que Montero Aroca desarrolló por años y que, finalmente, recompiló en un libro titulado de esa forma, a propósito de su discurso de investidura como Doctor Honoris Causa en la Univesidad Jaime I de Castellón (España), al respecto, véase MONTERO (2014), passim.

${ }^{77}$ Si bien es cierto, como indica Taruffo: "Si se piensa en un «buen» juez, capaz de ejercer correctamente y racionalmente sus poderes, no hay razón de temer que él se vuelva parcial, e incapaz de valorar las pruebas, por el sólo hecho de haber dispuesto o sugerido su adquisición. Sólo si se piensa en un juez incapaz y psíquicamente débil se puede temer que él pierda su propia imparcialidad en el momento en que decide sobre la oportunidad que una prueba ulterior sea adquirida, o que no sea capaz de sólo valorar una prueba de modo equilibrado porque ha sido por él dispuesta", TARUFFO (2006), p. 120.

${ }^{78}$ En este sentido, SALIDO (2016), pp. 232-245. Sin embargo, este fenómeno es mucho más discutible en el ámbito civil, véase HUNTER (2015), pp. 82-88.

${ }^{79}$ MIRANDA et al. (2012), p. 234.
} 


\section{5. ¿Podrían cumplir este rol nuestros jueces?}

Sin duda. Pese a que no se puede llegar a afirmar categóricamente el rol específico que desarrollan en los acuerdos, mediante la revisión meramente documental que permite el sistema de consulta unificada de causas, lo cierto es que puede intuirse que, en algunas ocasiones, los jueces apuestan por permitir acuerdos reparatorios que, incluso, son revertidos por las Cortes de Apelaciones, pero que demuestran la capacidad de permitir la disposición del objeto litigioso, como veremos a continuación. Para lograr esta demostración hemos seleccionado algunos casos paradigmáticos que prueban que se trata de un escenario posible. No significa, empero, que sea el supuesto más habitual, sino simplemente una posibilidad plausible.

Es decir, se observa, como en los ejemplos que mostramos un poco más adelante, que algunos jueces de garantía permiten arribar a acuerdos que, en su apariencia, no concuerdan a la perfección con la literalidad de lo prescrito en el CPP. De este modo, podemos deducir que se trata de supuestos en que el juzgador entiende que cuando los partícipes principales en los hechos llegan a un acuerdo puede ser una mejor opción que la imposición de una pena, cumpliéndose así efectos preventivos; racionalizando las consecuencias que son propias del Derecho penal, atendido su carácter de ultima ratio, tal como se resaltó supra. ${ }^{80}$

Probablemente, entonces, si es que están de conformes en que ese método de solución paccionado es positivo para las partes y para el Estado en su conjunto, es lógico pensar que también pudieran llegar a un rol más activo, con propuestas quizá más afinadas, más coherentes con otras y, en definitiva, más justas. Por poner un ejemplo, si en un acuerdo reparatorio se evalúa la conveniencia de ofrecer un monto remuneratorio compensatorio, es probable que un juez que autoriza este tipo de prácticas, pueda ayudar a las partes a ver qué monto es habitual, o "normal". ${ }^{81}$

Ejemplos de aquello, hay en nuestra jurisprudencia. La Corte de Apelaciones de Antofagasta $^{82}$ ha dado alguna señal a favor de "devolver" el conflicto a las partes haciendo lecturas bien tolerantes de los requisitos legales. Así, en el caso de un supuesto de robo en lugar habitado y pese a la gravedad de la pena, se aprobó el acuerdo reparatorio debido a que quedó en condición de frustrado y se razonó que la víctima no había sufrido perjuicio patrimonial, ni moral. Las partes del conflicto querían poner fin con una disculpa. Finalmente, entonces, la Corte entendió que concurren los requisitos, pese a existir acuerdos reparatorios con anterioridad por parte del imputado. En el aire queda esta corriente que prefiere privatizar el conflicto penal bajo algunas circunstancias.

\footnotetext{
${ }^{80}$ Con detalle, CARNEVALI (2017), p. 122-132, p. 131, donde se expone como los mecanismos alternativos, propios de la justicia restaurativa, pueden cumplir con los efectivos preventivos generales y especiales.

${ }^{81}$ Sin proponer una participación activa, pero reconociendo los beneficios de la participación del juez en este tipo de cometidos: "Es en este momento en que el juez puede y debe intervenir, por ejemplo, adecuando los montos indemnizatorios conforme a la solvencia del imputado y no solo en atención a lo demostrado por la víctima, para que así no aparezca que un sector notoriamente con mejores recursos económicos quede al margen del sistema penal en esta clase de delitos, adquiriendo ellos el carácter de un costo o una clase de compraventa", RETAMAL (2001), p. 123-144, p. 142.

${ }^{82}$ Corte de Apelaciones de Antofagasta, Causa Rol 407/2010, de 13 de enero de 2011.
} 
La misma Corte de Antofagasta y en el contexto de un robo en lugar habitado o destinado a habitación, es decir en una situación muy similar, resolvió en forma opuesta. ${ }^{83}$ En esta otra ocasión, no muy distante en el tiempo, realzó el carácter de pluriofensivo del delito para concluir que no resulta procedente aceptar un acuerdo reparatorio en este tipo de delitos, pues existe un interés público prevalente.

Para finalizar con estas muestras de Antofagasta ${ }^{84}$, en un supuesto de robo en lugar habitado, la Corte vuelve a razonar que la víctima no evidenció afectación de otros bienes jurídicos protegidos que la propiedad y debe privilegiarse el interés de la víctima y la solución pacífica e integral del conflicto jurídico. Para culminar con una máxima que compartimos: "Desconocer los intereses de la víctima en este caso concreto, significa violar los principios básicos de una sociedad justa que privilegiaría la sanción por la solución pacífica restauradora de vivir con calidad”.

Parece, más sencillo, aceptar los acuerdos en caso de robo en lugar no habitado. Pese a que como la Corte de Apelaciones de Rancagua ${ }^{85}$ declara son delitos de carácter pluriofensivo. Existen, entonces, en nuestra jurisprudencia varios ejemplos. ${ }^{86}$

\section{Palabras finales}

Desde hace ya un tiempo viene afirmándose que la pena no estaría cumpliendo de manera satisfactoria los fines que de ella se espera, fundamentalmente para la víctima, en cuanto no contiene un efectivo carácter reparador. Amén de los cuestionamientos desde la perspectiva resocializadora, más aún si se trata de penas privativas de libertad, sobre todo por su carácter segregador y estigmatizador. ${ }^{87}$ Todo ello hace necesario impulsar mecanismos que autorizan al imputado y a la víctima a solucionar el conflicto, como son, por ejemplo, los acuerdos reparatorios. Lo anterior conlleva una serie de ventajas que no pueden ser menospreciadas. Por de pronto, que cada uno se conozca a través de encuentros permite que el imputado al relacionarse directamente con el sujeto pasivo comprenda los efectos del hecho delictivo y el drama que pudo haber causado a la víctima, reforzando su proceso de reinserción, y por parte de la víctima, qué habría llevado al autor a cometer el hecho. Como se subrayó supra, los fines del Derecho penal también se pueden cumplir con otros

\footnotetext{
${ }^{83}$ Corte de Apelaciones de Antofagasta, Causa Rol 255/2011, de 29 de septiembre de 2011.

${ }^{84}$ Corte de Apelaciones de Antofagasta, Causa Rol 164/2011, de 29 de junio de 2011.

${ }^{85}$ Corte de Apelaciones de Rancagua, Causa Rol 277/2018, de 27 de abril de 2018.

${ }^{86}$ Podemos complementar esta afirmación con causas como la Corte de Apelaciones de Punta Arenas, Rol 66/2018, de 22 de mayo de 2018 en que en un delito de maltrato de obra a Carabineros se observó la existencia de interés público prevalente, pese a que los agentes aceptaron las disculpas; también en el Juzgado de Garantía de Chillan, RIT 6596-2017, de 2 de marzo, se aprobó acuerdo reparatorio en un caso de amenaza simple en que el imputado tenía condenas previas por robo con intimidación, amenazas simples y porte de arma de fuego; la Corte de Apelaciones de Antofagasta, Rol 62-2018, ratificó un acuerdo obtenido apropósito de un robo en lugar habitado o destinado a la habitación puesto que, solamente, es potencialmente pluriofensivo. Si bien es cierto que existen, más a menudo, ejemplos como el de la Corte de Apelaciones de Antofagasta, Rol 68-2018, de 19 de febrero en que se revocó un acuerdo reparatorio por ser pluriofensivo y existir conducta pretérita del imputado, pese a que las partes habían llegado a un acuerdo en que la víctima rechazó una suma de 500.000 pesos y, simplemente, aceptó las disculpas del victimario.
}

${ }^{87}$ LIBEDINSKY VENTURA (2004), pp. 10 y ss. 
instrumentos, diversos a las penas o a las medidas de seguridad. En este marco se inscriben los acuerdos reparatorios, los que no solo permiten descongestionar el sistema, ${ }^{88}$ al buscar la solución en etapas tempranas, sino que además, se materializan fines que son propios de las sociedades democráticas, como es procurar disponer de diversas herramientas de solución no gravosas e igualmente eficaces a través de una participación activa y en condiciones de igualdad.

El papel que puede cumplir el juez penal en la promoción de acuerdos reparatorios, al dirigir el debate procurando la conciliación, le otorga a mayor grado de legitimidad al acuerdo. Como se expuso, ello no importa cuestionar su imparcialidad.

${ }^{88}$ Ya planteado por CORTÉS-MONROY DE LA FUENTE (2000), p. 287. 


\section{Bibliografía citada}

ALVARADO, Adolfo (1989): Introducción al estudio del derecho procesal (Santa Fe: Rubinzal-Culzoni).

BLANCO, Rafael; HERNÁNDEZ, Héctor; RoJAs, Hugo (2005): "Las salidas alternativas en el Nuevo Proceso Penal Chileno", en: Colección de Investigaciones Jurídicas (Universidad Alberto Hurtado) $\left(\mathrm{N}^{\circ} 8\right)$, pp. 1-108.

BORDALÍ, Andrés (2009): "El derecho fundamental a un tribunal independiente e imparcial en el ordenamiento jurídico chileno", en: Revista de Derecho (Valparaíso) $\left(\mathrm{N}^{\mathrm{o}} 33\right)$, pp. 263-302.

BOVINO, Alberto (2005): Principios políticos del procedimiento penal (Buenos Aires: Editores del Puerto).

CALAMANDREI, Piero, Elogio de jueces escrito por un abogado, Madrid: Reus, 2009.

CARNEVALI, Raúl (2008): "Derecho Penal como ultima ratio. Hacia una política criminal racional”, en: Ius et Praxis, Año 14, $\mathrm{N}^{\circ} 1(2008)$, pp. 13-48.

CARNEVALI, Raúl (2017): "La justicia restaurativa como mecanismo de solución de conflictos. Su examen desde el derecho penal”, en: Justicia Juris (vol. 13, $\mathrm{N}^{\mathrm{o}} 1$ ), pp. $122-132$.

CASARINO, Mario (2011): Manual de Derecho Procesal. Derecho Procesal Orgánico. Tomo I, (Santiago: Editorial Jurídica de Chile), tomo I.

CASTRO, Javier (2017): Manual de Derecho Procesal Penal (Santiago: Libromar).

CERDA, Rodrigo, Nueva visión del juicio oral penal (Santiago: Librotecnia).

CHAUÁN, Sabas (2004): “Apelación de acuerdo reparatorio aprobado (RUC $\mathrm{N}^{\circ}$ 0310004886-7). Fallo recurso de queja (Rol de ingreso en Corte Suprema $N^{\circ} 3163$ 04). Comentario", en: Boletín del Ministerio Público ( $\left.\mathrm{N}^{\circ} 20\right)$, pp.132-140.

CHAUÁN, Sabas (2007): Manual del nuevo procedimiento penal (Santiago: LexisNexis).

CHIOVENDA, Guiseppe (2005): Instituciones de Derecho Procesal Civil (Buenos Aires: Valletta Ediciones).

COLOMBO, Juan (2014): Los actos procesales (Santiago: Editorial Jurídica de Chile).

CORTÉS-MONROY, Jorge (2000): "El Código Procesal Penal - las salidas alternativas al proceso y los procedimientos simplificado y abreviado como instrumento de descongestión del sistema procesal penal", en: Anuario - Facultad de Ciencias Jurídicas ( $\left.\mathrm{N}^{\circ} 16\right)$, pp. 281-302.

COUTURE, Eduardo (2010): Fundamentos del Derecho Procesal Civil (Buenos Aires: Euros Editores).

DE MARTINO, Francesco (1937): La giurisdizione nel diritto romano (Padova: Cedam).

DE VICENTE Y CARAVANTES, José (1856): Tratado histórico, crítico, filosófico de los procedimientos judiciales en materia civil, según la nueva Ley de enjuiciamiento; con sus correspondientes formularios (Madrid: Gaspar y Roig).

DEL RÍO, Carlos; ROJAS, Francisco (1999): De la Reforma Procesal Penal (Santiago: Conosur).

DELGADO, Joaquín (2000): El juicio de faltas (Barcelona: Bosch).

DUCE, Mauricio, RIEGO, Cristián (2009): Proceso penal (Santiago: Editorial Jurídica de Chile).

DUCE, Mauricio (2014): "Algunas reflexiones sobre los derechos de las víctimas en el proceso penal chileno", en: Política Criminal (Vol. 9 N$\left.^{\circ} 18\right)$, pp. 739-815. 
DUCE, Mauricio (2013): "La Reforma a la Reforma Procesal Penal", en: Anuario de Derecho Público ( $\mathrm{N}^{\circ}$ 1), pp. 110-144.

DUCE, Mauricio (2000): "La suspensión condicional del procedimiento y los acuerdos reparatorios en el nuevo Código Procesal Penal”, en: CAROCCA, Álex et. al, El nuevo proceso penal (Santiago, Lexisnexis) pp. 139-171.

ECHEVERRÍA, Germán (2010): "Imparcialidad del Tribunal Oral en lo Penal: Tras la conquista de la garantía”, Revista de Derecho (Valdivia) (vol. XXIII, No 1), pp. 269310.

FERNÁNDEZ, Juan (2001): “Comentario a un comentario”, en: Boletín Ministerio Público (No3), pp. 80-81.

FERREIRO, Xulio (2005): La víctima en el proceso penal (Madrid: La Ley).

GALÁN, Candela (2005): Protección de la imparcialidad judicial: abstención y recusación (Valencia, Tirant lo Blanch).

HORVITZ, María Inés; LÓPEZ, Julián (2002): Derecho Procesal Penal Chileno. Principios, sujetos, medidas cautelares, etapa de investigación (Santiago: Editorial Jurídica de Chile).

HUNTER, Iván (2007): "Poderes del juez civil: algunas consideraciones a propósito del juez de familia”, en: Revista de Derecho (Valdivia) (vol. XX, No 1), pp. 205-229.

HUNTER, Iván (2015): La aplicación judicial del Derecho en el proceso civil. Doctrina, jurisprudencia y derecho comparado (Santiago, Thomson Reuters).

JIMÉNEZ, María Angélica (2004): Las salidas alternativas en el nuevo proceso penal. Estudio exploratorio sobre su aplicación (Santiago, Centro de Documentación Defensoría Penal Pública).

LIBEDINSKY, Sofía (2001): "Negociación y salidas alternativas", en: AA.VV., Seminario Reforma Procesal Penal. Universidad Católica de Temuco (Santiago, Editorial Conosur) p. 145-156.

LÓPEZ, Fernando (2013): Imparcialidad. Derecho a un juez no prevenido, Tesis Doctoral: Universidad Rey Juan Carlos I.

MÁRQUEZ, Álvaro (2009): "La doctrina social sobre la justicia restaurativa", Prolegómenos. Derechos y Valores (vol. XII, No 24), p. 59-75.

MARSHALL, Tony (1999): Restorative Justice (Nueva York: Editorial Overview).

MASCIOTRA, Mario (2014): Poderes-deberes del juez en el proceso civil (Buenos Aires: Astrea).

MATURANA, Cristian; MONTERO, Raúl (2010): Derecho Procesal Penal (Santiago: Abeledo Perrot), tomo I.

MATUS, Jean Pierre (2011): "La justicia penal consensuada en el Nuevo Código de Derecho Procesal Penal”, en: MATUS, Jean Pierre, Derecho Penal, Criminología y Política Criminal en el cambio de siglo (Santiago, Editorial Jurídica de Chile), p. 53-80.

MIRANDA, Manuel; CERDA, Rodrigo; HERMOSILLA, Francisco (2012): Práctica de la prueba en el juicio oral. Su valoración y el estándar del "más allá de toda duda razonable" (Santiago: Librotecnia).

MONTERO, Juan (2014) La paradoja procesal del siglo XXI. Los poderes del juez penal (libertad) frente a los poderes del juez civil (dinero) (Valencia, Tirant lo Blanch). 
MORALES, Ana María; WELSCH, Gheman; HURTADO, María Teresa (2015): Estudio comparado sobre Tribunales de Ejecución de Penas (Santiago: Fundación Paz Ciudadana).

NEIRA, Eugenio (1993): Manual de Procedimiento Penal Chileno: Primera Instancia, (Santiago: Fallos del Mes).

ORTELLS, Manuel (1993): "Jurisprudencia del TEDH sobre el art. 6 del CEDH en el proceso penal (La doctrina de la "noción autónoma de materia penal". Derechos a un tribunal independiente e imparcial y a que la causa sea oída equitativamente. Presunción de inocencia)", en: La jurisprudencia del Tribunal Europeo de Derecho Humanos. Consejo General del Poder Judicial, ( $\left.\mathrm{N}^{\circ} 11\right)$, pp. 175-213.

PALOMO, Diego (2010): "Sobre las dificultades que genera la compresnión de las posiblidades y extensión del interrogatorio judicial en el marco de un proceso penal acusatorio-adversarial", en: Revista de Derecho (Coquimbo) (Año 17, $\mathrm{N}^{\mathrm{o}} 2$ ), pp. 301-324.

PALOMO, Diego, MATAMALA, Pedro (2012): "Los problemasde los poderes ex officio del juez laboral. Ahora a propósito de la potestad conciliatoria", en: Ius et Praxis (Año 18, $\mathbf{N}^{\circ} 1$ ), pp. 459-456.

PICÓ, Joan (2007): El juez y la prueba (Barcelona: Bosch).

RAMOS, Franciscov (2014): Enjuiciamiento criminal. Undécima lectura constitucional, (Barcelona: Atelier).

RETAMAL, Jaime (2011): "Las salidas alternativas en el Nuevo Código Procesal Penal", Revista de Derecho (CDE) ( ${ }^{\circ}$ 5), p. 123-144.

RODRÍGUEZ, Manuel; PINO, Octavio (2015): “Análisis de la (in)eficacia del principio de obligatoriedad en el ejercicio de la acción penal en la etapa preliminar del proceso penal chileno", en: Revista de Derecho (Coquimbo) (vol. 22, Nº1), pp. 351-399.

ROJAS, Luis Emilio (2001): "Reparación y sanción penal en un acuerdo reparatorio convenido ante el Juez de Garantía de Pucón”, en: Boletín Ministerio Público ( $\mathrm{N}^{\circ}$ 2), pp. 48-51.

ROMERO, Alejandro (2017): "Comentario sobre el derecho al juez natural en el proceso penal acusatorio y el principio forum delicti commissi”, en: Revista Jurídica Digital UAndes ( $\left.\mathrm{N}^{\circ} 2\right)$, pp. 109-116.

RUA, Gonzalo; GONZÁLEZ, Leonel (2018): "El rol del juez en un sistema adversarial. Fundamentos y técnicas de conducción de audiencias", en: Sistemas Judiciales (Año $\left.17, \mathrm{~N}^{\mathrm{o}} 21\right)$, pp. 80-103.

SALIDO, María Belén (2016): El iura novit curia y su incidencia en el derecho de defensa en juicio y en la garantía de la imparcialidad del juzgador (Montevideo - Buenos Aires, BdeF).

SAMPEDRO-ARRUBLA, Julio (2010): "La justicia restaurativa: una nueva vía, desde las vícitimas, en la solución al conflicto penal", International Law. Revista Colombiana de Derecho Internacional, ( $\left.{ }^{\circ} 17\right)$, pp. 87-124.

SCHÜNEMANN, Bernd (1971): Grund und Grenzen der unechten Unterlassungsdelikte. Zugleich ein Beitrag zur strafrechtlichen Methodenlehre (Göttingen).

SERRA, Manuel (2008): Jurisdicción, acción y proceso, (Barcelona: Atelier).

TARUFFO, Michele (2006): "Poderes probatorios de las partes y el juez en Europa" en: Ius et Praxis (Año 12, $\mathrm{N}^{\circ}$ 2), pp. 95-122. 
VALDECABRES, María Isabel (2004): Imparcialidad del juez y medios de comunicación, (Valencia, Tirant lo Blanch).

VALDÉS, Remberto (2004): "El proceso. La imparcialidad. Sistema inquisitivo y acusatorio. La concepción unitaria del proceso. La constitución política y los tratados de derechos humanos", en: Revista del Consejo de Defensa del Estado (No 12), s/p.

VALLESPÍN, David (2002): El modelo constitucional de juicio justo en el ámbito del proceso civil, (Barcelona: Atelier).

VÁZQUEZ, José Luis (2014): "De la "iudisdictio in sola notione consistit" a la prevalencia de la ejecución”, en: RAMOS MÉNDEZ, Francisco (dir.) Hacia una gestión moderna y eficaz de la ejecución (Barcelona: Atelier).

VIDELA, Lino (2010): “Los acuerdos reparatorios a la luz del concepto de reparación”, en: Revista de Estudios de la Justicia (N 13), pp. 293-321.

VON WRIGHT, Georg (1997): Normas, verdad y lógica (México DF: Fontamara).

WACH, Adolf (2016): Conferencias sobre la Ordenanza Procesal Civil alemana (Buenos Aires: Ara Editores).

ZÁRATE, Manuel (2000): “Los acuerdos reparatorios. Comentarios desde su regulación normativa, de las nociones de reparación y negociación y desde la práctica", en: Derecho y Humanidades (No 9), pp. 125-146.

\section{Jurisprudencia citada}

Ministerio Público con Muñoz (2018): Corte de Apelaciones de Rancagua 27 de abril de 2018 (recurso de apelación).

Ministerio Público con Araya (2018): Corte de Apelaciones de Antofagasta 19 de febrero de 2018 (recurso de apelación).

Parra Viscay con juez subrogante Juzgado Garantía de Yungay (2018): Corte de Apelaciones de Chillán 14 de julio de 2016 (recurso de amparo constitucional).

Lemos Jería con jueza del Juzgado de Garantía de Talcahuano (2014): Corte de Apelaciones de Concepción 4 de junio de 2014 (recurso de amparo constitucional).

Ministerio público con Kodzoma (2011): Corte de Apelaciones de Antofagasta, 13 de enero de 2011 (recurso de apelación).

Ministerio Público con Díaz (2011): Corte de Apelaciones de Antofagasta 29 de septiembre de 2011 (recurso de apelación).

Ministerio Público con Pinto (2011): Corte de Apelaciones de Antofagasta 29 de junio de 2011 (recurso de apelación). 